\title{
Optimization of a Rapid Propagation System for Mass Production of High-Quality Plantlets of Trichosanthes kirilowii cv. 'Yuelou-2' via Organogenesis
}

\author{
Jin-Jin CHEN, Yuan-Shan ZHANG, Xiao-Dong CAI* \\ Yangtze University, College of Horticulture and Gardening, Jingzhou, Hubei 434025, \\ China;Chen_JinJin0@163.com; realzys1994@163.com; caixiao.dong@163.com (*orrespondingauthor)
}

\begin{abstract}
Trichosanthes kirilowii Maxim is a perennial plant possessing great medicinal and edible value. In this study, an efficient rapid propagation system was developed for in vitro production of high-quality plantlets of $T$. kirilowii cv. 'Yuelou-2' via organogenesis. Shoots were established from the nodal stems of this plant by cultured on Murashige and Skoog (MS) basal medium containing different concentrations of naphthalene acetic acid (NAA), indole-3-butyric acid (IBA) and 6benzyladenine (6-BA) according to a $\mathrm{L}_{9}\left(3^{4}\right)$ orthogonal array design. MS medium supplemented with $0.5 \mathrm{mg}^{-1} 6-\mathrm{BA}$ alone conferred significant enhancement of shoot induction and development by variance and statistical analysis of shoot induction frequency, shoot length, as well as lateral shoot number and total node number per explant. Rooting percentage, root morphological characteristics, plantlet survival rate, as well as plantlet growth performance in vitro and ex vitro were comprehensively assessed, and results showed that the addition of $1.0 \mathrm{mg}^{1-1} \mathrm{NAA}$ to $1 / 2 \mathrm{MS}$ medium was the most responsive for root induction and production of high-quality plantlets from the regenerated shoots. The in vitro propagation system described here has the potential for large-scale and rapid production of in vitro plantlets of seed variety of $T$. kirilowii in a sustainable manner.
\end{abstract}

Keywords: in vitro; morphological characterization; plant growth regulator; rapid propagation; Trichosanthes kirilowii

\section{Introduction}

Trichosanthes kirilowii Maxim is a perennial climbing herbaceous plant of the Cucurbitaceae family, which is valued for its numerous medicinal functions (Shu et al., 2009; Lo et al., 2017), abundant nutritional components (Huang et al., 2000; Wang et al., 2009; Zheng et al., 2015), and potential ornamental characteristics (Yu et al., 2009; Zhao et al., 2018). Trichosanthin, a ribosome inactivating protein purified from the root tubers, has been considered as an abortifacient, immunosuppressive and anti-tumor protein, and may be used as a potent inhibitor against HIV1 replication (Li et al., 1991; Shaw et al., 2005). Recently, seeds of T. kirilowii have gained increasing popularity in China because of their good taste, extraordinary nutrients and medicinal values (Huang et al., 2000; Wang et al., 2009; Zheng et al., 2015). However, the native populations of $T$. kirilowii have gradually declined in China due to overharvesting for its broad medicinal values. Therefore, efforts should be dedicated to produce a sufficient quantity of $T$. kirilowii plants by artificial propagation so as to meet the increasing demands of this industry.

Conventionally, T. kirilowii is reproduced by seeds or vegetatively propagated via root tubers. This species is a dioecious plant, and a ratio of male to female of about 1: 10 is suitable in production for harvesting fruits or seeds (Zheng et al., 2015). However, it is common that only about 30\% seedlings were female when propagated by seeds (Guo et al., 2009). Moreover, propagation by seeds is undesirable because of high heterozygosis of the seedlings. Currently, vegetative propagation by division of root tubers is the main methods for reproduction of $T$. kirilowii, while this method has a relatively low reproductive rate and tends to be labour intensive and costly, which limits the production of adequate plants to growers. Tissue culture techniques offer a powerful tool for mass clonal propagation of elite, rare and threatened plant species (Sarasan et al., 2006). The potential of in vitro propagation of T. kirilowii initiated from stem segments, leaf tissues and roots, etc., has been widely explored during the past decades (Zheng et al., 2001; Guo et al., 2009; Yu et al., 2009; Xu et al., 2015; Zhao et al., 2018). Most of these researches tried to establish an 
efficient protocol for in vitro plant regeneration from seedling or wild materials of $T$. kirilowii by using different kinds and concentrations of plant growth regulators (PGRs), and an efficient rapid propagation system for in vitro propagation of cultivated seed varieties of this plant has not yet been detailed. Presently, the demand of seed $T$. kirilowii plants is increasing in China (Zheng et al., 2015). Thus further studies of an optimized PGRs combination for mass propagation of seed varieties of $T$. kirilowii in vitro should be investigated.

In addition, acclimatization to ex vitro conditions of tissue cultured plantlets is an important step in micropropagation. In vitro derived plantlets are commonly cultured under controlled conditions, which may result in anatomical abnormalities (Asayesh et al., 2017) and biochemical changes such as oxidative stress (Resende et al., 2016) during acclimatization. Therefore, a relatively high mortality of in vitro plantlets during laboratory to land transfer often occurs (EL-Kazzaz et al., 2018). Hence, it is essential for a successful micropropagation system that increasing the survival rate and ensuring healthy growth of the in vitro plantlets at acclimatization stage. Previous reports suggested that the quality of in vitro plants has an important influence on subsequent acclimatization and plant growth in the field (Padilla et al., 2003; Barrales-López et al., 2015). Thus, regeneration of healthy and vigorously growing plantlets is also vital for large-scale in vitro culture of seed varieties of T. kirilowii.

'Yuelou-2', a seed variety of $T$. kirilowii, exhibited remarkable traits such as large seeds, abundant nutrition, strong disease resistance and high yield (Zheng et al., 2015). Herein, nodal stems of female 'Yuelou-2' were used as explants to induce shoots by cultured on MS basal medium supplemented with different concentrations of NAA, IBA and 6-BA according to an orthogonal array design, and root induction as well as plantlet acclimatization were also carried out. Most efforts were directed towards enhancing the performance of the regenerated shoots and the rooting plantlets, with the aim to establish an efficient and reproducible rapid propagation system for in vitro production of high-quality plantlets of seed T. kirilowii.

\section{Materials and Methods}

Plant material and explants establishment

Young shoots of greenhouse-grown female plants of $T$. kirilowii cv. 'Yuelou-2' were collected and washed under running tap water for $20 \mathrm{~min}$. Then they were surfacedisinfected with $70 \%$ (v/v) alcohol for $30 \mathrm{sec}$ followed by $0.5 \%(\mathrm{w} / \mathrm{v})$ sodium dichloroisocyanuric acid for $20 \mathrm{~min}$. After being rinsed in sterile water three times, the explants were surface-dried with sterile filter papers, followed by sectioned aseptically into nodal stems of approximately 1.5 $\mathrm{cm}$ in length.

\section{Shoot induction medium and conditions}

To determine an optimal medium for shoot induction and development, a $\mathrm{L}_{9}\left(3^{4}\right)$ orthogonal experimental design with three factors (6-BA, IBA and NAA) was performed as listed in Table 1. All media were based on MS basal medium contained $30 \mathrm{~g} \mathrm{l}^{-1}$ sucrose and $7.5 \mathrm{~g} \mathrm{l}^{-1}$ agar, and the $\mathrm{pH}$ of all media was adjusted to 5.8 prior to autoclaving at $121{ }^{\circ} \mathrm{C}$ for $15 \mathrm{~min}$. The prepared nodal stems were inserted into the shoot induction medium (SIM), i.e., the SIM1 to SIM9 medium, respectively (Table 1 ). Four explants were cultured in a $100 \mathrm{ml}$ Erlenmeyer flask loaded with $40 \mathrm{ml}$ medium, and 16 explants were used in each treatment. All the treatments were repeated three times, and maintained in a growth room at $25 \pm 1{ }^{\circ} \mathrm{C}$ and $12 \mathrm{~h} / 12 \mathrm{~h}$ (light/dark) cycles under cool white fluorescent lamps (about 2500 Lux). Data were taken as total number of inoculated explants (N1), number of explants regenerated shoots ( $\geq 1 \mathrm{~cm}$ in length) (N2), main shoot length, as well as number of lateral shoot and total node per explant after 30 days of incubation. The shoot induction frequency was calculated by N2/N $1 \times 100 \%$.

\section{Root induction}

The regenerated shoots (about $5-6 \mathrm{~cm}$ in length) were excised and cut into nodal cuttings (about $1.0 \mathrm{~cm}$ in length), and then placed on the rooting medium (RM), i.e., solidified $1 / 2 \mathrm{MS}$ basal medium supplemented with $0,0.2$, 0.5 or $1 \mathrm{mg} \mathrm{l}^{-1} \mathrm{NAA}$ (Table 4). All media contained 20 $\mathrm{gl}^{-1}$ sucrose, $7.5 \mathrm{~g} \mathrm{l}^{-1}$ agar and $0.5 \mathrm{~g} \mathrm{l}^{-1}$ activated charcoal (AC), with $\mathrm{pH}$ adjusted to 5.8. Twenty explants in each of three replicates per treatment performed in $100 \mathrm{ml}$ flasks were used, and all cultures were maintained under the same condition as mentioned in the above for 30 days. In vitro parameters including total number of shoots transferred onto rooting medium (N3), number of shoots with roots (N4), root number per shoot, root length, and plantlet height were evaluated after 30 days from the start of the experiment. The rooting rate was calculated by N4/N3×100\%.

Table 1. Orthogonal L9 $\left(3^{4}\right)$ array and results of the shoot induction and development of T. kirilowii cv. 'Yuelou-2' after 30 days of culture

\begin{tabular}{|c|c|c|c|c|c|c|c|}
\hline \multirow{2}{*}{ Treatments } & \multicolumn{3}{|c|}{ Factors $\left(\mathrm{mgl}^{-1}\right)$} & \multirow{2}{*}{$\begin{array}{l}\text { Shoot induction } \\
\text { frequency (\%) }\end{array}$} & \multirow{2}{*}{$\begin{array}{l}\text { Main shoot } \\
\text { length }(\mathrm{cm})\end{array}$} & \multirow{2}{*}{$\begin{array}{c}\text { Lateral shoot } \\
\text { number/explant }\end{array}$} & \multirow{2}{*}{$\begin{array}{c}\text { Total node } \\
\text { number/explant }\end{array}$} \\
\hline & A & B & $\mathrm{C}$ & & & & \\
\hline SIM1 & $1(0)$ & $1(0)$ & $1(0)$ & $91.7 \pm 3.6$ & $2.06 \pm 0.25$ & $0.00 \pm 0.00$ & $4.02 \pm 0.14$ \\
\hline SIM2 & $I(0)$ & $2(0.2)$ & $2(0.2)$ & $93.8 \pm 6.3$ & $5.17 \pm 0.54$ & $1.71 \pm 0.25$ & $7.12 \pm 0.28$ \\
\hline SIM3 & $1(0)$ & $3(0.5)$ & $3(0.5)$ & $95.8 \pm 3.6$ & $5.30 \pm 0.50$ & $4.76 \pm 0.70$ & $7.92 \pm 0.17$ \\
\hline SIM4 & $2(0.2)$ & $I(0)$ & $2(0.2)$ & $89.6 \pm 3.6$ & $5.15 \pm 1.11$ & $2.24 \pm 0.67$ & $6.76 \pm 0.94$ \\
\hline SIM5 & $2(0.2)$ & $2(0.2)$ & $3(0.5)$ & $88.9 \pm 3.9$ & $5.14 \pm 0.95$ & $0.33 \pm 0.34$ & $6.16 \pm 0.81$ \\
\hline SIM6 & $2(0.2)$ & $3(0.5)$ & $1(0)$ & $62.5 \pm 12.5$ & $2.09 \pm 0.13$ & $0.25 \pm 0.25$ & $4.60 \pm 1.10$ \\
\hline SIM7 & $3(0.5)$ & $I(0)$ & $3(0.5)$ & $72.9 \pm 9.5$ & $2.25 \pm 0.78$ & $0.17 \pm 0.14$ & $4.18 \pm 0.90$ \\
\hline SIM8 & $3(0.5)$ & $2(0.2)$ & $I(0)$ & $58.3 \pm 3.6$ & $1.51 \pm 0.47$ & $0.67 \pm 0.52$ & $3.21 \pm 0.94$ \\
\hline SIM9 & $3(0.5)$ & $3(0.5)$ & $2(0.2)$ & $66.7 \pm 9.5$ & $1.65 \pm 0.42$ & $0.00 \pm 0.00$ & $4.13 \pm 1.13$ \\
\hline
\end{tabular}


724

\section{Acclimatization and growth of regenerated plantlets}

After 30 days in rooting medium, the rooted plantlets were carefully rinsed under running tap water to remove residual medium on the surface of the roots. The plantlets were marked according to the root induction medium from which they were regenerated. Then the plantlets were transplanted individually to plastic pots (upper diameter: $10.0 \mathrm{~cm}$; bottom diameter: $8.0 \mathrm{~cm}$; height: $8.5 \mathrm{~cm}$, drainage holes in the bottom) filled with a commercial potting mix for acclimatization. Next, the plants were maintained in a climate chamber incubator at a temperature range of 20-28 ${ }^{\circ} \mathrm{C}$, an intensity of illumination of approximately 3000 Lux with a photoperiod of 12 hours and $65-80 \%$ relative humidity. Each treatment consisted of 48 regenerated plants (three replicates of 16 plantlets for each treatment). Thirty days later, transplanted plantlet number (N5), living plant number (N6), and growth parameters including the plant height, the lateral shoot number, the total node number and the above-ground fresh weigh of each plantlet were recorded. The survival rate was calculated by N6/N5 $\times 100 \%$.

\section{Statistical analysis}

Data from these measurements were analyzed by the SPSS version 19 software (SPSS Inc., Chicago, IL, USA), and the values are expressed as the Mean \pm SD. Prior to analysis, the percentage values including shoot induction frequency, rooting rate and the survival rate were arcsine transformed to normalize error distribution. Data were subjected to one-way analysis of variance (one-way
ANOVA), and significant differences between means were identified using least significant difference (LSD) at a significance level of $5 \%$.

\section{Results and Discussion}

\section{Shoot induction and development}

Shoots initiation was observed within 7 days of culture on all applied media including the SIM1 medium devoid of any PGRs, and gradually developed into shoots of different height after culture for 30 days (Fig. $1 \mathrm{~A}-\mathrm{D}$ ). Calli were also observed around the cut surfaces of the explants. After 30 days culture, explants on the SIM3 medium had a higher height together with a larger callus size (Fig. 1A) compared with the others, whereas both the SIM8 (Fig. 1B) and the SIM9 medium (Fig. 1D) were observed to suppress shoot elongation. Furthermore, many roots were also observed on the explants incubated on the SIM7 medium as shown in Fig.1C. It has been reported that shoots could be obtained by culturing the callus induced from leaf or stem tissues of T. kirilowii on shoot induction medium (Zhao et al., 2018). However, the calli turned brown gradually and had no capability of shoot regeneration, as might be that the media were not suitable for callus differentiation and proliferation in this study.

As is well known, cytokinin and auxin interact to regulate many plant developmental processes and morphogenesis of in vitro cultured explants (Schaller et al., 2015). PGRs such as NAA, IBA and 6-BA were used

Table 2. Range analysis of the $\mathrm{L}_{9}\left(3^{4}\right)$ array for the shoot induction and development of T. kirilowii cv. 'Yuelou-2' after 30 days of culture

\begin{tabular}{|c|c|c|c|c|}
\hline \multirow{2}{*}{ Variables } & \multirow{2}{*}{ Levels } & \multicolumn{3}{|c|}{ Mean } \\
\hline & & $\mathrm{A}$ & $\mathrm{B}$ & $\mathrm{C}$ \\
\hline \multirow{7}{*}{$\begin{array}{l}\text { Shoot induction } \\
\text { frequency (\%) }\end{array}$} & K1 & 93.75 & 84.72 & 70.83 \\
\hline & K2 & 80.32 & 80.32 & 83.33 \\
\hline & K3 & 65.97 & 75.00 & 85.88 \\
\hline & Range & 27.78 & 9.72 & 15.05 \\
\hline & Primary and secondary order of factors & \multicolumn{3}{|c|}{$\mathrm{A}>\mathrm{C}>\mathrm{B}$} \\
\hline & Excellent level & Al & B1 & $\mathrm{C} 3$ \\
\hline & Optimal combination & & $\mathrm{A} 1 \mathrm{~B} 1 \mathrm{C}$ & \\
\hline \multirow{7}{*}{ Main shoot length $(\mathrm{cm})$} & $\mathrm{K} 1$ & 4.18 & 3.15 & 1.89 \\
\hline & K2 & 4.13 & 3.94 & 3.99 \\
\hline & K3 & 1.80 & 3.01 & 4.23 \\
\hline & Range & 3.0 & 0.93 & 2.34 \\
\hline & Primary and secondary order of factors & \multicolumn{3}{|c|}{$\mathrm{A}>\mathrm{C}>\mathrm{B}$} \\
\hline & Excellent level & $\mathrm{Al}$ & B2 & $\mathrm{C} 3$ \\
\hline & Optimal combination & & $\mathrm{A} 1 \mathrm{~B} 2 \mathrm{C}$ & \\
\hline \multirow{7}{*}{$\begin{array}{c}\text { Lateral shoot } \\
\text { number/explant }\end{array}$} & $\mathrm{K} 1$ & 2.16 & 0.81 & 0.31 \\
\hline & K2 & 0.95 & 0.90 & 1.33 \\
\hline & K3 & 0.28 & 1.67 & 1.75 \\
\hline & Range & 1.88 & 0.86 & 1.44 \\
\hline & Primary and secondary order of factors & \multicolumn{3}{|c|}{$A>C>B$} \\
\hline & Excellent level & $\mathrm{Al}$ & B3 & $\mathrm{C} 3$ \\
\hline & Optimal combination & \multicolumn{3}{|c|}{ A1B3C3 } \\
\hline \multirow{7}{*}{$\begin{array}{c}\text { Total node } \\
\text { number/explant }\end{array}$} & $\mathrm{K} 1$ & 6.35 & 4.99 & 3.94 \\
\hline & K2 & 5.84 & 5.50 & 6.00 \\
\hline & K3 & 3.84 & 5.55 & 6.09 \\
\hline & Range & 2.51 & 0.56 & 2.15 \\
\hline & Primary and secondary order of factors & \multicolumn{3}{|c|}{$\mathrm{A}>\mathrm{C}>\mathrm{B}$} \\
\hline & Excellent level & $\mathrm{Al}$ & B2 & $\mathrm{C} 3$ \\
\hline & Optimal combination & \multicolumn{3}{|c|}{$\mathrm{A} 1 \mathrm{~B} 2 \mathrm{C} 3$} \\
\hline
\end{tabular}


Table 3. Variance analysis of the effects NAA, IBA and 6-BA concentrations on the shoot induction and development of T. kirilowii cv. 'Yuelou-2' after 30 days of culture

\begin{tabular}{|c|c|c|c|c|c|c|}
\hline Shoot parameters & Source of variance & Degree of freedom & $\begin{array}{c}\text { Type III sum of } \\
\text { squares }\end{array}$ & Mean square & $F$ value & P value \\
\hline \multirow{4}{*}{$\begin{array}{l}\text { Shoot induction frequency } \\
\qquad(\%)\end{array}$} & NAA & 2 & $2,400.435$ & $1,200.218$ & 17.470 & $0.000^{* *}$ \\
\hline & IBA & 2 & 193.853 & 96.926 & 1.411 & 0.267 \\
\hline & $6-\mathrm{BA}$ & 2 & 151.782 & 75.891 & 1.105 & 0.351 \\
\hline & Error & 20 & $1,374.011$ & 68.701 & & \\
\hline \multirow{4}{*}{ Main shoot length } & NAA & 2 & 37.659 & 18.830 & 12.041 & $0.000^{* *}$ \\
\hline & IBA & 2 & 7.739 & 3.869 & 2.474 & 0.110 \\
\hline & $6-\mathrm{BA}$ & 2 & 7.220 & 3.610 & 2.308 & 0.125 \\
\hline & Error & 20 & 31.276 & 1.564 & & \\
\hline \multirow{4}{*}{$\begin{array}{c}\text { Lateral shoot } \\
\text { number/explant }\end{array}$} & NAA & 2 & 17.157 & 8.578 & 5.012 & $0.017^{*}$ \\
\hline & IBA & 2 & 1.354 & 0.677 & 0.396 & 0.678 \\
\hline & $6-\mathrm{BA}$ & 2 & 7.171 & 3.586 & 2.095 & 0.149 \\
\hline & Error & 20 & 34.228 & 1.711 & & \\
\hline \multirow{4}{*}{$\begin{array}{c}\text { Total node } \\
\text { number/explant }\end{array}$} & NAA & 2 & 33.333 & 16.666 & 11.098 & $0.001^{* *}$ \\
\hline & IBA & 2 & 5.476 & 2.738 & 1.823 & 0.187 \\
\hline & 6-BA & 2 & 15.166 & 7.583 & $5.049^{*}$ & 0.017 \\
\hline & Error & 20 & 30.036 & 1.502 & & \\
\hline
\end{tabular}

extensively in previous shoot induction of T. kirilowii (Zheng et al., 2001; Yu et al., 2009; Guo et al., 2009; Zhao et al., 2018). Thus modulating the concentration of PGRs may help improve shoot induction and elongation. Orthogonal design is an efficient method of studying the effects of multifactor and multilevel, which has been widely used for establishment of a successful tissue culture method for diverse plants like Eucalyptus grandis $\times$ E. urophylla (Oliveira et al., 2017). In this study, a L9 $\left(3^{4}\right)$ orthogonal design was performed as listed in Table 1 with the aim to determine an optimal PGRs combination for shoot induction and growth (Table 1). According to the range analysis of the orthogonal test, the effects of the three factors on shoot induction frequency, shoot length, as well as lateral shoot number and total node number per explant all decreased in the following order: $\mathrm{A}>\mathrm{C}>\mathrm{B}$, i.e., the concentration of NAA was the most determinant factor for the shoot induction and development (Table 2). Further one-way ANOVA analysis revealed that NAA had an extremely significant effect $(p<0.01)$ on the shoot regeneration frequency, and both IBA and BA had no significant effect on the shoot induction frequency (Table 1 and 3). In addition, NAA was showed to extremely significantly reduce the main shoot length and the total node number per explant $(p<0.01)$, and also significantly decreased the lateral shoot number per explant $(p<0.05)$ (Table 1 and 3). For IBA and BA, results showed that both of them had no significant effects on the main shoot length and the lateral shoot number per explant, while a higher concentration of BA significantly increased the node number per explant $(p<0.05)$ (Table 1 and 3 ).

Producing sufficient high-quality shoots is a perquisite for mass in vitro propagation of $T$. kirilowii. Of the three parameters for evaluating the shoot development, the node number per explant was a determinate factor for shoot and plantlet multiplication rate as the nodal stems were an ideal explant source for in vitro propagation of T. kirilowii.
Therefore, taking into account these results and cost of IBA, it can be inferred that the A1B1C3 combination (MS+0.5 $\mathrm{mg} \mathrm{l}^{-1}$ 6-BA) is the optimum medium for yielding a higher induction frequency of shoots with vigorous growth of $T$. kirilowii cv. 'Yuelou-2'. The important role of 6-BA in the shoot induction and development of T. kirilowii has been identified by several reports (Zheng et al. 2001; Yu et al., 2009; Sun et al., 2014). In this study, $0.5 \mathrm{mg} \mathrm{l}^{-1}$ 6-BA alone was proven to be the most efficient for regeneration of highquality shoots. The opposite result was recorded in $T$. cucumerina, another species of Trichosanthes, in which NAA along with BA in the culture medium promoted higher number of shoot multiplication than BA alone (Devendra et al., 2008). This different response is probably due to differences in plant species.

Effects of different concentration of $N A A$ on root induction and plantlets growth

After 30 days culture in the rooting medium, plantlets with adventitious roots were regenerated from almost all the inoculated nodal stems on the RM1 (Fig. 2 A), RM2 (Fig. 2 B), RM3 (Fig. 2 C) and RM4 medium (Fig. 2 D). However, the root number per culture differed greatly among the four rooting media. For example, only several adventitious roots with little lateral roots were obtained on the RM1 medium (Fig. 2 E), whereas many robust adventitious roots with a number of lateral roots were observed on the RM4 medium (Fig. 2 F). The rooting rate was all above $90 \%$ on the four media including the RM1 medium without NAA, and statistic results showed that it was not significantly different among all NAA concentrations tested (Table 4). Great rooting percentage was also obtained in previous in vitro studies of T. kirilowii (Zheng et al., 2001; Yu et al., 2009; Guo et al., 2009; Zhao et al., 2018). This suggested that the roots were readily formed from the nodal stems of $T$. kirilowi in vitro. 


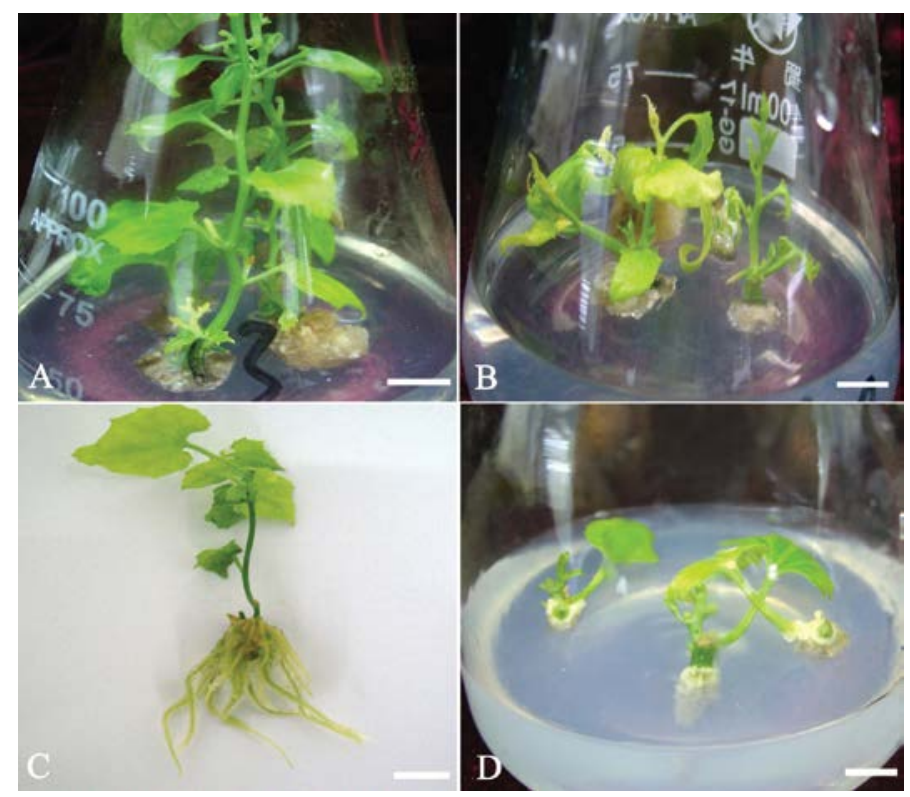

Fig. 1. Shoot regeneration from the nodal stems of T. kirilowii cv. Yuelou-2 after 30 days of culture on MS basal medium supplemented with different concentrations of 6-BA, IBA and NAA according to a $\mathrm{L}_{9}\left(3^{4}\right)$ orthogonal array design. Regenerated shoots on the SIM3 medium containing $0.5 \mathrm{mg} \mathrm{l}^{-1} \mathrm{IBA}$ and $0.5 \mathrm{mg} \mathrm{l}^{-1} 6$-BA (A), the SIM8 medium containing $0.5 \mathrm{mg} \mathrm{l}^{-1} \mathrm{NAA}$ and $0.2 \mathrm{mg} \mathrm{l}^{-1} \mathrm{IBA}(\mathrm{B})$, the SIM7 medium containing $0.5 \mathrm{mg} \mathrm{l}^{-1} \mathrm{NAA}$ and $0.5 \mathrm{mg} \mathrm{l}^{-1} 6-\mathrm{BA}(\mathrm{C})$, and the SIM9 medium containing $0.5 \mathrm{mg} \mathrm{l}^{-1} \mathrm{NAA}, 0.5 \mathrm{mg} \mathrm{l}^{-1} \mathrm{IBA}$ and $0.2 \mathrm{mg} \mathrm{l}^{-1} 6-\mathrm{BA}(\mathrm{D})$. Bars $=1 \mathrm{~cm}$

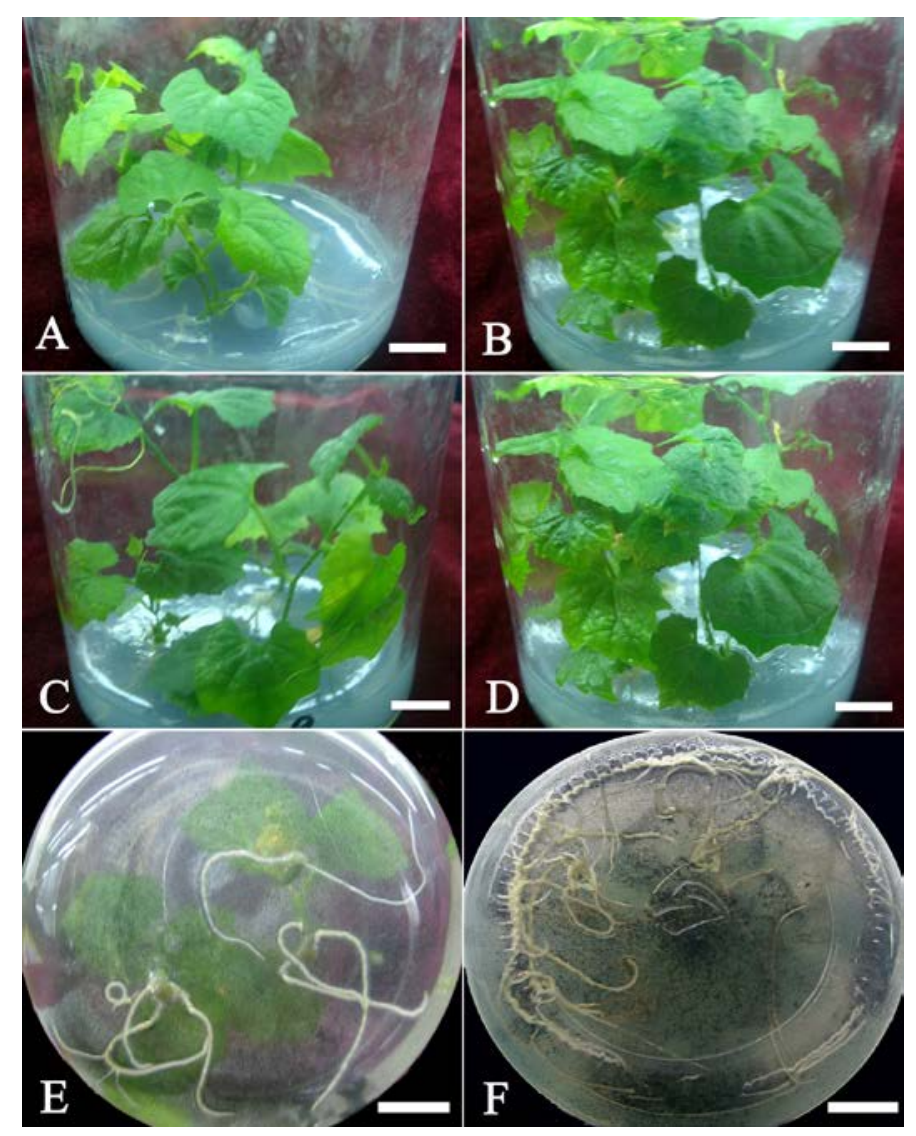

Fig. 2. Plantlet regeneration from the regenerated shoots of T. kirilowii cv. Yuelou-2 cultured on MS basal medium containing different concentration of NAA for 30 days. Rooted plantlets regenerated from the RM1 medium without NAA (A), the RM2 medium containing $0.2 \mathrm{mg} \mathrm{l}^{-1} \mathrm{NAA}(\mathrm{B})$, the RM3 medium containing $0.5 \mathrm{mg} \mathrm{l}^{-1} \mathrm{NAA}(\mathrm{C})$, and the RM4 medium containing 1.0 $\mathrm{mg} \mathrm{l}^{-1}$ NAA (D). E. Several adventitious roots with little lateral roots induced on the RI1 medium; F. Many adventitious roots with a number of lateral roots induced on the RI4 medium. Bars $=1 \mathrm{~cm}$ 
It is well known that improving the quality of in vitro rooted plantlets is essential for increasing the survival rate and plantlet growth during acclimatization (Padilla $e t$ al., 2003; Barrales-López et al., 2015). Root morphological characteristics such as root number and root length are important factors in determining plant growth and development, and optimization of rooting medium is an effective way to enhance root induction and elongation ( $\mathrm{Liu}$ et al., 2013).

In this study, the highest root number per culture was observed in the cuttings treated by $1.0 \mathrm{mg} \mathrm{l}^{-1} \mathrm{NAA}$, i.e., the RM4 medium, which was significantly higher compared to the other media $(p<0.05)$. For the root length, the RM1 medium ( $0 \mathrm{mg} \mathrm{l}^{-1} \mathrm{NAA}$ ) was observed to have a significant promotion effect compared with the media containing NAA, among which no significant difference was found $(p<0.05) \quad$ (Table 4). This suggested that a higher concentration of NAA could induce more adventitious roots from the nodal stems of $T$. kirilowii, but it significantly inhibited the root elongation in this study. Similar results were reported by Aremu et al. (2016), in which the medium containing NAA caused about two-fold reduction of root length of the regenerates. In addition, results showed that the plantlet height increased with the increasing of NAA concentration in the medium. The $1 \mathrm{mg}$ $1^{-1} \mathrm{NAA}$, i.e., the RM4 medium achieved the highest plantlet height $(4.96 \mathrm{~cm})$ among the treatments, which was significantly higher than that of the RM1 and RM2 medium 30 days after culture (Table 4).

Effect of different rooting media on survival rate and plantlets growth during acclimatization

The survival rate of the plantlets from different rooting media was clearly differed 30 days after transplantation in the plastic containers. As shown in Table 5, the highest survival rate was observed in the plantlets derived from the RM4 medium (89.58\%), followed by the RM3 (87.50\%), RM2 (33.33\%) and RM1 (18.75\%) medium. Statistical analysis showed that the survival rate of the plantlets from the RM4 medium was significantly higher than those from the RM1 and RM2 medium, while no significant difference was detected between the RM1 and RM2 medium, and between the RM3 and RM4 medium ( $p<0.05)$. Padilla et al.
(2003) reported that the survival rate of Prunus domestica plantlets was affected by the shoot height rather than the number and length of roots. Contrary to this report, our study suggested that the more root number formed, the higher survival rate of the acclimated plantlets reached. Similar results had also been reported in a number of plants such as Sorghum bicolor (Liu et al., 2013).

Plantlet growth status was also an important indicator reflecting the quality of the regenerated plantlets during acclimatization, as was assessed after 30 days of transplanting (Table 5). Among the four treatments, the plantlets from the RM4 medium grew more vigorously with $33.74 \mathrm{~cm}$ of the mean plant height, 2.0 of the mean lateral shoot number per plantlet, 33.44 of the average node number per plantlet, and $6.90 \mathrm{~g}$ of the mean above-ground fresh weight per plantlet, which were significantly higher than those from the RM1 and RM2 treatment, respectively. The plants with a good root system were generally considered to be more vigorous and tolerant of adverse environmental conditions, and root number was considered as a promising trait for early plant vigor among other root architectural properties (Colombi and Walter, 2017). Micropropagated plantlets may suffer various abiotic stresses due to morphological, anatomical and environmental changes during acclimatization to ex vitro conditions (Resende et al., 2016; Asayesh et al., 2017). Therefore, development of a healthy root system is vital for reducing plantlet loss and improving plantlet growth during acclimatization process and subsequent growth in fields. The results of this study could be explained by a better root system from the RM4 medium could absorb more nutrients and water from the potting mix thereby enhancing the growth of the plantlets. It was noticed that the survived plantlets transplanted from the RM1 medium showed poor growth vigor, and the mean plant height only increased from $3.36 \mathrm{~cm}$ to $5.23 \mathrm{~cm}$ (Table 4), and no lateral branch was formed after 30 days. This might be attributed to the fact that the reduction of root number resulted in limited nutrient absorption, thus affecting the growth and development of the plantlets. Therefore, the results further confirmed that the RM4 medium, i.e., $1 / 2 \mathrm{MS}+1.0 \mathrm{mg} \mathrm{l}^{-1}$ NAA was the best medium for root induction of $T$. kirilowii in vitro.

Table 4. Effects of different concentration of NAA on root induction and plantlets growth of T. kirilowii cv. 'Yuelou-2' after 30 days of culture

\begin{tabular}{ccccc}
\hline Treatment & NAA $\left(\mathrm{mgl}^{-1}\right)$ & Rooting rate $(\%)$ & Root number/shoot & Root length $(\mathrm{cm})$ \\
\hline RM1 & 0 & $91.7 \pm 8.3 \mathrm{a}$ & $2.06 \pm 0.52 \mathrm{c}$ & $5.33 \pm 0.12 \mathrm{a}$ \\
RM2 & 0.2 & $94.4 \pm 5.1 \mathrm{a}$ & $2.89 \pm 0.36 \mathrm{c}$ & $4.62 \pm 0.17 \mathrm{~b}$ \\
RM3 & 0.5 & $97.2 \pm 4.3 \mathrm{a}$ & $4.62 \pm 0.41 \mathrm{~b}$ & $3.36 \pm 0.21 \mathrm{~b}$ \\
RM4 & 1.0 & $94.6 \pm 4.8 \mathrm{a}$ & $5.61 \pm 0.51 \mathrm{a}$ & $4.60 \pm 0.50 \mathrm{a}$ \\
\hline
\end{tabular}

Note: Mean values with the same letters are not significant differences (LSD test, $p<0.05$ ).

Table 5. Effects of different rooting media on the survival rate and plantlets growth of T. kirilowii cv. 'Yuelou-2' after acclimatization for 30 days

\begin{tabular}{ccccc}
\hline Treatment & $\begin{array}{c}\text { Survival rate } \\
(\%)\end{array}$ & $\begin{array}{c}\text { Plantlet height } \\
(\mathrm{cm})\end{array}$ & $\begin{array}{c}\text { Lateral shoot } \\
\text { number/plantlet }\end{array}$ & $\begin{array}{c}\text { Total node } \\
\text { number/plantlet }\end{array}$ \\
\hline RM1 & $18.75 \pm 6.25 \mathrm{~b}$ & $5.23 \pm 0.33 \mathrm{~d}$ & $1.00 \pm 0.00 \mathrm{~b}$ & $8.78 \pm 0.19 \mathrm{c}$ \\
RM2 & $33.33 \pm 9.55 \mathrm{~b}$ & $16.67 \pm 0.33 \mathrm{c}$ & $1.22 \pm 0.38 \mathrm{~b}$ & $18.44 \pm 3.15 \mathrm{~b}$ \\
RM3 & $87.50 \pm 6.25 \mathrm{a}$ & $28.42 \pm 2.04 \mathrm{~b}$ & $1.89 \pm 0.19 \mathrm{a}$ & $30.67 \pm 1.67 \mathrm{a}$ \\
RM4 & $89.58 \pm 7.22 \mathrm{a}$ & $33.74 \pm 0.96 \mathrm{a}$ & $2.00 \pm 0.33 \mathrm{a}$ & $33.44 \pm 2.71 \mathrm{a}$ \\
\hline
\end{tabular}

Note: Mean values with the same letters are not significant differences (LSD test, $\mathrm{p}<0.05$ ). 


\section{Conclusions}

In the present study, an efficient rapid propagation protocol for in vitro production of high-quality plantlets of T. kirilowii cv. 'Yuelou-2' was developed. Results of the morphological characteristics of the regenerated shoots and plantlets (in vitro and ex vitro) indicated that the protocol was as follows: Firstly the disinfected nodal stems of about $1.5 \mathrm{~cm}$ length were cultured on MS basal medium supplemented with $0.5 \mathrm{mg} \mathrm{l}^{-1} 6-\mathrm{BA}$ for 30 days to induce sufficient shoots with vigorous growth, and then the regenerated shoots were cut into nodal cuttings (about 1.0 $\mathrm{cm}$ in length) and maintained on 1/2 MS medium supplemented with NAA for 30 days to induce regeneration of high-quality plantlets. These results will support future large-scale fast multiplication of in vitro plantlets of seed variety of T. kirilowii.

\section{Acknowledgements}

This work was supported by funds of the Scientific Research Project of Hubei Education Department of China (No. B2018024).

\section{References}

Aremu AO, Plačková L, Pěnčik A, Novák O, Doležal K, Van Staden J (2016). Auxin-cytokinin interaction and variations in their metabolic products in the regulation of organogenesis in two Eucomis species. New Biotechnology33(6):883-890.

Asayesh ZM, Vahdati K, AliniaeifardS (2017). Investigation of physiological components involved in low water conservation capacity of in vitro walnut plants. Scientia Horticulturae 224:1-7.

Barrales-López A, Robledo-Paz A, Trejo C, Espitia-Rangel E, Rodríguez-De La OJL (2015). Improved in vitro rooting and acclimatization of Capsicum chinense Jacq. plantlets. In Vitro Cellular \& Developmental Biology-Plant 51(3):274-283.

Colombi T, Walter A (2017). Genetic diversity under soil compaction in wheat: root number as a promising trait for early plant vigor. Frontiers in PlantScience 8:420.

Devendra NK, Rajanna L, Sheetal C, Seetharam YN (2008). In vitro clonal propagtion of Trichosanthes cucumerina $\mathrm{L}$. var. cucumerina. Plant Tissue Culture and Biotechnology 18(2):103-111.

EL-Kazzaz AA, Ebad FA, EL-Sadek MEA (2018). Acclimation of potato via in vitro microtubers versus plantlets under saline conditions. Scientia Agriculturae 21(2):49-56.

Guo XL, Wang M, Shu SH (2009). Tissue culture of male and female Trichosanthes kirilowii Maxim. Journal of Wuhan Botanical Research 27(6):684-687 (in Chinese with English abstract).

Huang Y, He P, Bader KP, Radunz A, Schmid GH (2000). Seeds of Trichosanthes kirilowii, an energy-rich diet. Zeitschrift für Naturforschung 55(3-4):189-194.

Li MX, Yeung HW, Pan LP, Chan SI (1991). Trichosanthin, a potent HIV-1 inhibitor, can cleave supercoiled DNA in vitro. Nucleic Acids Research 19(22):6309-6312.

Liu GQ, Gilding EK, Godwin ID (2013). Additive effects of three auxins and copper on sorghum in vitro root induction. In Vitro Cellular \& Developmental Biology-Plant 49(2):191-197.

Lo HY, Li TC, Yang TY, Li CC, ChiangJH, Hsiang CY, Ho TY (2017). Hypogycemic effects of Trichosanthes kirilowii and its protein constituent in diabetic mice: the involvement of insulin receptor pathway. BMC Complementary and Alternative Medicine 17(1):53.

Oliveira C, Degenhardt-Goldbach J, Bettencourt GMF, Amano E, Franciscon L, Quoirin M (2017). Micropropagation of Eucalyptus grandis $\times$ E. urophylla AEC 224 clone. Journal of Forestry Research 28(1):29-39.

Padilla IMG, Webb K, Scorza R (2003). Early antibiotic selection and efficient rooting and acclimatization improve the production of transgenic plum plants (Prunus domestica L.). Plant Cell Reports 22(1):38-45.

Resende CF, Braga VF, Pereira PF, Silva CJ, Vale VF, Bianchetti RE, ... Peixoto PHP (2016). Proline levels, oxidative metabolism and photosynthetic pigments during in vitro growth and acclimatization of Pitcairnia encholirioides L.B. Sm. (Bromeliaceae). Brazilian Journal of Biology 76(1):218-227.

Sarasan V, Cripps R, Ramsay MM, Atherton C, McMichen M, Prendergast $\mathrm{G}$, Rowntree JK (2006). Conservation in vitro of threatened plantsprogress in the past decade. In Vitro Cellular \& Developmental BiologyPlant 42(3): 206-214.

Schaller GE, Bishopp A, Kieber JJ (2015). The yin-yang of hormones: cytokinin and auxin interactions in plant development. The Plant Cell 27(1):44-63.

Shaw PC, Lee MK, Wong KB (2005). Recent advances in trichosanthin, a ribosome-inactivating protein with multiple pharmacological properties. Toxicon 45(6):683-689.

Shu SH, Xie GZ, Guo XI, Wang M (2009). Purification and characterization of a novel ribosome-inactivating protein from seeds of Trichosanthes kirilowii Maxim. Protein Expression and Purification 67(2):120-125.

Wang WF, Wang LZ, Jiang JX (2009). Fatty acid profile of Trichosanthes kirilowii Maxim. seed oil. Chemical Papers 63(4):489-492.

Xu KD, Chang YX, ZhangJ, Wang PL, Wu JX, Li YY, ... Li CW (2015). A lower $\mathrm{pH}$ value benefits regeneration of Trichosanthes kirilowii by somatic embryogenesis, involving rhizoid tubers (RTBs), a novel structure. Scientific Reports 5:8823.

Yu HL, Hu YH, Li J (2009). Study on rapid propagation in vitro of medicinal Plant Trichosanthes kirilowii. Hubei Agricultural Sciences 48(2):272-274(in Chinese with English abstract).

Zhao FL, Wang R, Xue JP, Duan, YB (2018). Efficient callus-mediated regeneration and in vitro root tuberization in Trichosanthes kirilowii Maxim, a medicinal plant. In Vitro Cellular \& Developmental BiologyPlant 54(6):621-625.

Zheng Q, Sun YF, Yang AX, Xing H, Zhao H (2015). New variety of highyielding Trichosanthes kirilowii var. Yuelou-2. Journal of Changiang Vegetables 23:22 (in Chinese).

Zheng SS, Yuan HY, Wang LJ, An CC, Chen ZL (2001). The tissue culture of medicinal plant Trichosanthes kirilowii and its protein analysis. Chinese Journal of Biotechnology 17(4):420-422 (in Chinese with Engish abstract). 